That syphilis had existed amongst mankind in all ages and countries, under circumstances similar to those in which it is said to have first appearcd in Europe, I have already stated it to be my opinion; but of the pontaneous cure of this malady (by which 1 mean its entire disappearance without the aid of mediciue), it was reserved for the present age to establish the proof; and of this I shall speak hereafter. It will now be necessary for me to proceed to the description of those parts of the body which are generally the recipients of the syphilitic virus, and the seat of what are called its primary symptoms.

\section{CASE OF TETANUS,}

WITH OBSERVATIONS ON THIS AFFECTION GENERALLY.

Ijy Jhmes B. Thompson, A.B., M.D., Surgeon, \&c. \&c.

Jomn Sullivan, ætat. 29, a public-house proprietor, of good robust general health, was in the summer of 1835 , while assisting in the act of getting a puncheon of whiskey off the dray, caught between the end of the puucheon and the kerbstone of the footway, the other assistants having incautiously allowed the puncheon to slide off too suddenly, and before he was made acquainted with their having done so : the whole weight consequently pressed upon him, and his indexfinger of the right hand was shattered, about the middle of the second joint; the bone was actually pulverised, and the finger was only kept together by the portion of skin and muscle which happened to have remained whole.

This occurred on the Saturday evening, and the man suffered the most excruciating pain during the latter part of that night, and got hourly worse, all the aggravated symptoms of this complaint presenting themselves, such as spastic rigidity of the muscles of the neck, the body being forcibly drawn forwards; difficulty in swallowing; the abdominal muscles strongly retracted; suppression of urine; eyes fixed ; tongue protruded; forehead corrugated; frightful distortion of the whole expression of the countenance; occasional violent and sudden contractions (often causing the patient to scream most piteously) of the parts particularly engaged in this rigid state; the respiration and circulation very greatly disturbed; the former scemed purely effected by the diaphragm.

I visited this patient on the following morning, and suggested to the friends the only remedy which $I$ thought would give the patient a chance of his life. This was the removal of the finger beyond the point lacerated or injured; but the friends objected, and, of course, the operation was not attempted, and the poo rman died in about thirty-two hours from the occurrence of this unfortunate accident.

I was denied a post-mortem examination, for which I was most anxious, in order to examine the particular parts engaged in this disease, more especially the heart, brain, and lungs. I was led to suppose that there was effusion on the brain, from the unusually dilated state of the pupils, that of the left eye in particular. Why this difference, as to the dilatation in the right and left eye, I cannot take upon me to offer an opinion; but it struck me as being very remarkable: the injury, too, occurring in the right hand. Perhaps some one of your many contributors may be disposed to throw some light on this subject, as I do not feel disposed to connect this peculiar occurrence with the generally-supposed decussation of the optic nerves. Could there be any physiological information derived from the recent discovery of Dr. Marshall Hall, on the reflex action or function of nerves in such anomalous occurrences as the foregoing? I would here also wish to ask, what were the chances of an operation at the period at which I saw this patient? My own feeling would lead me to suppose it would have been very doubtful. Still I may be pernitted to add, that under the circumstances there was nothing else that I could with any propriety recommend. There was some opium, \&c. administered to this patient before $I$ had seen him; but it was impossible to get him to take anything at or after I visited him. The teeth were firmly clenched together, not admitting of the spatula to get between.

33, Upper Gower-street, University College, Dec. 10, 1841.

\section{SUCCESSFUL OPERATION}

\section{FOR}

\section{PROLAPSUS OF THE WOMB.}

\section{To the Editor of The LANCET.}

SIR,-My friend, Mr. William Morday, of Sunderland, has sent me the rough notes of a successful operation for prolapsed womb: you will perhaps agree with me in thinking the case worthy of publication. I remain, Sir, yours obediently,

\section{0, Henrietta-street, Strand,} N. S. MORRIS. Dec. 6, 1841 .

Mary Robson, ætat. 41, widow, and mother of six children, of short stature and broad pelvis, consulted me in March last for a procidentia uteri. She stated that she always felt a bearing down of the womb for some time after each confinement, but since she had the last child, having had a difficult labour, now nearly ten years ago, the womb appeared externally, and every effort made to replace and retain it failed, and it has 